\title{
A new department for injuries and violence prevention at the World Health Organization
}

\author{
E G Krug, A Butchart, M Peden
}

Intentional and unintentional injuries represent approximately $11 \%$ of the global mortality and $13 \%$ of all disability adjusted life years lost every year. Recognising the magnitude of the problem, the World Health Organization (WHO) has recently taken important steps to increase its injury prevention activities. In March 2000, a Department for Injuries and Violence Prevention (VIP) was created. For the first time, in 50 years, injuries and violence prevention now has a place on the WHO organizational chart.

The department is located in the Cluster for Non-Communicable Diseases and Mental Health. Injuries and violence prevention is not a new area of work in WHO. WHO has conducted activities in this area for more than two decades. However, the human resources and attention devoted to the topic have recently increased dramatically.

The mission of VIP is to spearhead global action to prevent violence and unintentional injuries as major threats to public health. Its goals are to:

- Act as a facilitating authority for international science based prevention efforts.

- Promote and facilitate international research.

- Promote improved standards of teaching and training.

- Foster multidisciplinary collaboration between relevant global, regional, and national stakeholders.

- Compile and disseminate "best practices" for violence and unintentional injury prevention and control.

- Facilitate implementation of violence and unintentional injury prevention and control at country level.

- Collate, analyse, and disseminate global data on violence and unintentional injuries.

To date, most injury prevention efforts have occurred in high income countries. And yet, low and middle income countries have higher injury mortality rates than high income countries in all regions of the world. Therefore it is urgent to develop strategies that are appropriate, cost efficient, and effective in low and middle income countries, taking into account the complexity of the problem in these countries and the experience from what works in other countries. Developing strategies with low and middle income countries is a main focus for VIP.
VIP has two teams: violence prevention and unintentional injuries prevention, and three cross sectional areas of work: surveillance, prehospital care, and advocacy (see fig 1).

The following is a brief description of some of the current activities of VIP.

\section{Surveillance}

Data are essential for policy making. However, information on the burden of injuries and violence is poor. To help remedy this situation, VIP and its partners have developed tools to facilitate data collection and analysis. Guidelines on landmine injury surveillance have been published and widely disseminated, and guidelines for injury surveillance in less resourced environments will be released before the end of 2001. In 2001, version 1 of the International Classification for External Causes of Injuries (ICECI) was also released and these instruments are already being used in many countries. In addition, WHO has provided technical assistance for data collection to several countries, including Afghanistan, Ethiopia, Mozambique, Nicaragua, and Uganda. A multicountry study on alcohol and injuries was initiated in collaboration with WHO's Department for Mental Health and Substance Dependence. To build capacity in Africa, an injury epidemiology course prepared in collaboration with the Injury Prevention Initiative for Africa was given to representatives from eight African countries.

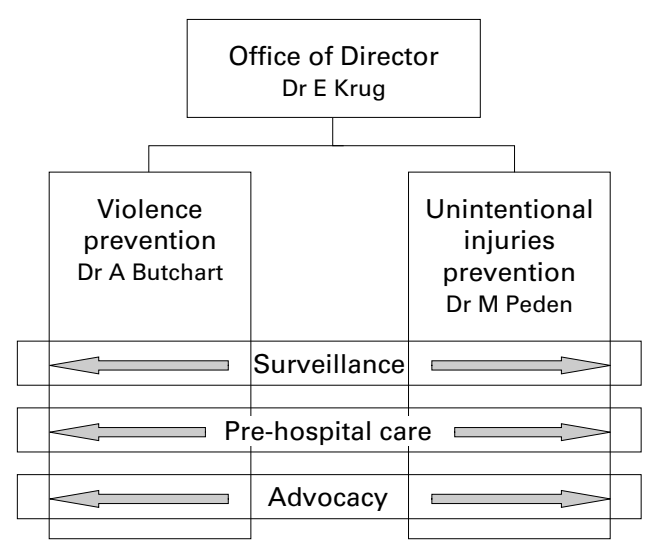

Figure 1 WHO Violence and Injury Prevention Department. 
Violence prevention

VIP's violence prevention work has two elements: development of the World Report on Violence and Health, and the violence prevention framework activities. The World Report on Violence and Health was initiated in March 1999. The report will be the first global publication to explore violence as a major public health challenge. The goals of the report are to raise awareness worldwide about the public health aspects of violence and to highlight the contribution that public health can make to better understanding and preventing the problem. More than 50 authors and peer reviewers from around the world contributed to the preparation of the first draft of the report that was completed in October 2000. Based on the comments received during a series of six regional consultations with an additional 70 violence prevention experts, a final document is being prepared for release in 2002. The report will be written for public health practitioners and researchers, and a concise summary report will be produced for policy and other decision makers. Excerpts from the report will be discussed in the WHO Executive Board meeting in January 2002.

The second element, the violence prevention framework, is intended to provide guidance to countries and to donor agencies interested in investing in violence prevention. Activities related to the framework include three main areas. First, development of the violence prevention framework itself, through extensive consultation with other United Nations' agencies, member states, non-governmental organizations, and violence prevention experts in other sectors. This framework will consist of a series of advocacy documents and a summary document that outlines the essential elements for violence prevention at national, regional, and global levels. Second the production of capacity development resources, such as guidelines to prevent and respond to the different types of interpersonal violence. Examples of guidelines that are under development include guidelines for the prevention of child abuse and neglect and guidelines to improve services for victims of sexual violence. Third, the implementation at country level of pilot violence prevention programmes. As a pilot project, VIP has facilitated the development of a national plan of action on violence prevention in Mozambique.

\section{Traffic injuries prevention}

In April 2001, VIP held a consultation with experts from around the world to develop and launch a five year strategy to prevent road traffic injuries. The strategy includes activities in the areas of epidemiology, prevention, and advocacy. The meeting resulted in the creation of new partnerships. The first activity resulting from the strategy will be the development of advocacy material to encourage action by public health agencies around the world. Also to be produced is a document describing "best practices". In addition, a network of researchers from developing countries was created in collaboration with the Global Forum for Health Research. The purpose of this network is to facilitate south-south and north-south partnerships in the conduct of research on traffic injury prevention in developing countries. During 2000, this network met in Uganda and in Thailand, to develop protocols for three studies. Furthermore, a meeting to develop prevention strategies for less resourced environments will be held at Harvard University in 2002 .

\section{Small arms}

In view of the growing threat to public health posed by small arms and the lack of reliable data about their health consequences, VIP has initiated the planning for a multicountry study. This study will assess the impact of small arms on health and thus inform policy making. A first step in this area has been the compilation of existing WHO data and scientific literature into a report entitled Small Arms and Global Health. The report was released at the July 2001 United Nations Conference on the Illicit Traffic of Small Arms and Light Weapons in All Its Aspects. From 2002 to 2004, surveys will be conducted in countries for which no data are available.

\section{Landmine victim assistance}

VIP has continued to provide input to the Ottawa process on landmines and to implement the joint International Committee of the Red Cross/WHO strategy. In addition to the development of standards for data collection, a framework for victim assistance was developed and technical assistance provided to Afghanistan, Bosnia, Ethiopia, Nicaragua, and Mozambique.

\section{Pre-hospital care}

Appropriate pre-hospital care could save hundreds of thousands of lives every year, yet is almost entirely lacking in many of the countries and regions with the highest rates of violence and unintentional injury. A consultation on this topic was held in 2000. This resulted in the creation of a network of experts who are now drafting guidelines for the improvement of prehospital care systems. In 1999, a course was held in South Africa to train trainers from 10 African countries, and training is being conducted in a number of countries including Angola, Cambodia, Iran, and Mozambique.

\section{Global injury prevention web site}

VIP is currently developing a multilanguage interactive injury prevention web site (www.who.int/violence_injury_prevention/). This site will reflect not so much the work currently being undertaken by WHO, but rather that being conducted in the regions and countries by the injury and violence prevention community. Furthermore, the site will contain multiple links to global sites that will lead the reader to more in-depth discussions on various topics. The aim is to create a global platform 
for exchange of information about documents, interventions, and events taking place around the world.

While VIP is the focal department at WHO for the prevention of injuries and violence, it is not the only department with something to offer the field. Other departments with important contributions include Child and Adolescent Health, Gender and Women's Health, Mental Health and Substance Dependence, Health Service Provision, and Evidence for Health Policy. These departments conduct activities aiming at better understanding the burden of violence against women or violence against healthcare workers, at strengthening the links between child rights and public health, or at measuring alcohol as a risk factor for injuries. In addition, the six WHO regional offices are also steadily increasing the amount of regional activities conducted in this field.

Although the number of activities conducted by WHO has increased greatly since the year 2000 , much more remains to be done. One of the keys to increasing the number of activities and thereby the visibility of injury prevention globally is to broaden partnerships. Over the years, the network of WHO Collaborating
Centres for injury prevention has provided extensive support and input in WHO activities. Among other activities, this network has facilitated the development of the International Classification for External Causes of Injuries, the creation of a network of Safe Communities, and the organization of five World Conferences on Injury Prevention and Control. The sixth conference is to be held in Montreal in May 2002 (www.trauma2002.org) and the seventh in Vienna in July 2004. Special efforts will be made during the coming months to broaden the network of partners for global injury prevention.

The challenges faced by WHO, such as strengthening political commitment and mobilizing funds, are in many ways similar to those faced by everyone working in this field. Overcoming these challenges will be difficult and will take time. Nevertheless, we have arrived at a unique moment where awareness and commitment are growing and where expertise for data collection and prevention is more readily available in many countries. The recent developments in WHO should be used by the global injury community to further its work at the national and local level. 